\title{
QUANTITATIVE AND COMPARATIVE STUDIES OF PHARMA- COLOGICAL FEATURES IN THE CORONARY, FEMORAL AND RENAL CIRCULATIONS WITH DIFFERENT CORONARY VASODILATORS
}

\author{
Katsunori OGURO and Koroku HASHIMOTO \\ Department of Pharmacology and Experimental Therapeutics, \\ Tohoku University School of Medicine, Sendai, Japan
}

Accepted July 25, 1973

\begin{abstract}
Effects of various coronary vasodilators on the coronary, the femoral and the renal circulations were compared with those of ritroglycerin, and classified on the basis of differences in the mode of action. Coronary vasodilators used in this study, caused a significant increase in the rate of both the coronary and the femoral blood flows while a slight increase or even a decrease in the rate of the renal blood flow was observed. The coronary vasodilating activity was in the following order; nifedipine $>$ nitroglycerin>iproveratril>dipyridamole, prenylamine, lidofiazinc, papaverine $>$ carbochromene, trapymin $>k$ hellin, which was approx. equivalent to $1: 1 / 3$ : 1/10:1/100:1/300:1/3000. The order of effectiveness of vasodilation in the coronary circulation produced by these compounds was similar to that observed in femoral circulation. Lidoflazine, dipyridamole, prenylamine, carbochromene and khellin, however, caused a dose-dependent vasoconstriction in renal circulation. A large dose of papaverine caused a diphasic response in the renal circulation. From these experimental results, lidoflazine, dipyridamole, carbochromene and khelline can be classificd as "specific coronary vasodilators", while nifedipine, nitroglycerin, iproveratril and trapymin are "non-specific coronary vasodilators". Papaverine and prenylamine do not appear to belong to these two categories.
\end{abstract}

Fam and McGregor (1) and Winbury ct al. (2, 3) demonstrated that in the canine coronary circulation, nitrate vasodilators caused a greater dilatation in the large arteries, and that these compounds also resulted in a prominent vasodilation in the hindlimb of dogs in the steady state (4). On the other hand, adenosine primarily acts on the small coronary arteries (5) as phosphorylated derivatives of adenosine cause mainly a relaxation in the nutritional arteries (6). Thus, vasodilation of the resting muscle is unremarkable. Previously, Hashimoto et al. $(7,8)$ detected a peculiar renal vasoconstriction caused by dipyridamole while the coronary, femoral and mesenteric arteries showed a vasodilation. Observations of these authors give support to the concept that vascular smooth muscles of peripheral circulation may behave differently under the infuence of various vasodilators.

In this study, vascular responses of peripheral organs to various coronary vasodilators in clinical use were examined and classification was attempted on the basis of differences in the mode of action in peripheral circulation. 


\section{MATERIALS AND METHODS}

One hundred and sixteen mongrel dogs of both sexes were used including animals from which fresh blood was obtained. Recipient dogs, about $10 \mathrm{~kg}$, werc anesthetized with $30 \mathrm{mg} / \mathrm{kg}$ of sodium pentobarbital i.v. and donor dogs over $20 \mathrm{~kg}$ with $15 \mathrm{mg} / \mathrm{kg}$ of morphine and $1 \mathrm{~g} / \mathrm{kg}$ of urethane s.c. Animals were heparinized with an i.v. administration of $400 \mathrm{U} / \mathrm{kg}$ of sodium heparin.

Arrangement for the coronary circulation: Coronary circulation of the normally beating heart of a recipient dog was cross-circulated with arterial blood led from the carotid artery of a donor dog using a Dalc-Schuster pump. A constant pressure perfusion at $100 \mathrm{mmHg}$ was arranged. The donor dog was artificially respired with a respirator (Harvard Apparatus Co., Model 607) at the rate of 20 cycles per min with a tidal volume of $20 \mathrm{ml} / \mathrm{kg}$. The perfusion pressure was monitored by an electromanometer (Nihon Kohden, RP-2). Rate of the coronary blood flow was determined by the total outflow leaving the pulmonary artery, using an electromagnetic flowmeter (Nihon Kohden, MF2). Heart rate was continuously recorded by a cardiotachometer (Nihon Kohden, RT-2) triggered by the R wave of ECG (lead II) on an ink-writing oscillograph (Nihon Kohden, WI-180). The technique used was the modified Langendorff's dog heart preparation with cross-circulation as described in detail in a previous paper (9).

Arrangement for the renal circulation: The kidney was perfused with blood led from the femoral artery at a constant pressure of $100 \mathrm{mmHg}$ with the aid of a peristaltic pump (Harvard Apparatus Co., Model 500-1200). Rate of the renal blood flow was measured by a method previously described (10).

Arrangement for the fomoral circulation: Cannulae were inserted into the proximal and distal ends of the cut femoral artery. These two cannulae were connected by rubber tubing. An electromagnetic flowmeter (Nihon Kohden, MF-2) was set between the two cannulae.

Systemic blood pressure was measured at the carotid artery by means of a pressure transducer (Nihon Kohden, RP-2), used in experiments for renal and femoral circulations.

Drugs tested were nifedipine (Bayer), nitroglycerin (Nihon Kayaku), iproveratril hydrochloride (Knoll), dipyridamole (Boehringer Ingerheim), prenylamine (Hoechst), lidoflazine (Janssen), trapymin (VEB Deutches Hytiewerk Rodleven), papaverine hydrochloride (Iwaki), carbochromene hydrochloride (Cassella-Riedel) and khellin (Chugai). A constant volume of $0.1 \mathrm{ml}$ of a drug solution was injected into the perfusion system close to the arterial cannula through the rubber tube over a $10 \mathrm{sec}$ period. Stock solutions were prepared as follows: Khellin was suspended in distilled water, iproveratril, lidoflazine and carbochromene were dissolved in $0.01 \mathrm{~N}-\mathrm{HCl}$ and other drugs in $0.9 \%$ saline. Desired concentration was obtaincd by dilution of the stock solution with $0.9 \%$ saline.

\section{RESULTS}

Control values of the flow rate in the coronary, femoral and renal circulations

Table 1 summarizes control values of the parameters on which the drug action was obscrved, 
TABLE 1. Basal flow rates of peripheral circulations.

\begin{tabular}{lcc}
\hline & Number of animals & Mcan $\perp$ S.E. \\
Coronary blood flow & 18 & $-\cdots$ \\
Femoral blood flow & 14 & $75.0 \pm 4.0 \mathrm{ml} / \mathrm{min}$. \\
Renal blood flow & 22 & $114.0 \pm 2.0 \mathrm{ml} / \mathrm{min}$. \\
\hline
\end{tabular}

Effects of various diugs on the rate of blood flow in the coronary, femoral and renal circulations

Typical patterns of drug responses in the coronary, femoral and renal circulations are shown in Fig. 1. Changes in these parameters after administration of the drugs are also depicted graphically as a percentage of each control value in Fig. 2.

Coronary blood flow (Left column of Fig. 1 and upper graph of Fig. 2): Nitroglycerin, nifedipine, iproveratril, dipyridamole, prenylamine, lidoflazine, trapymin, carbochromene, and papaverine caused an increase in the rate of the coronary blood flow, dose-dependently.
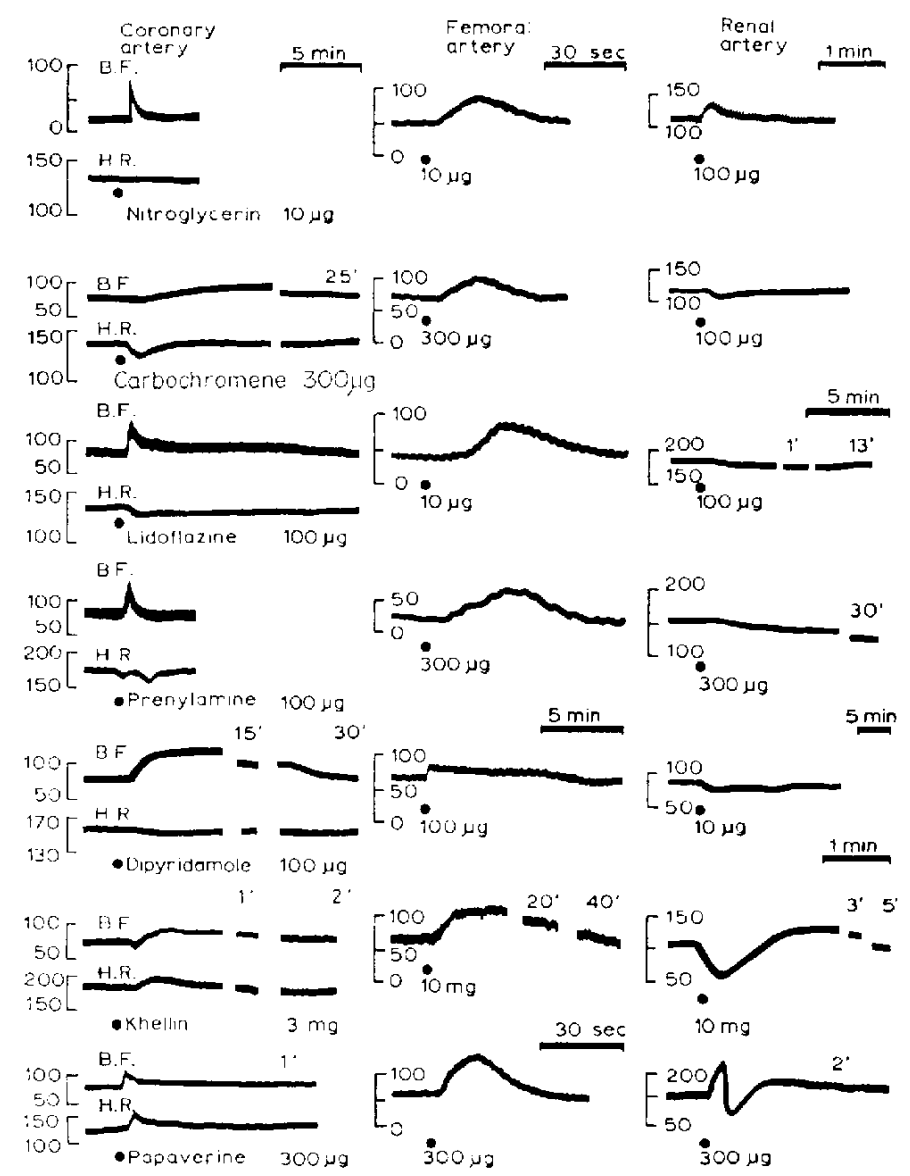

FiG. 1. Left, middle and right columns of this figure show typical patterns of response to various coronary vasodilators in coronary, femoral and renal circulations. BF ; blood flow, HR ; heart rate. 

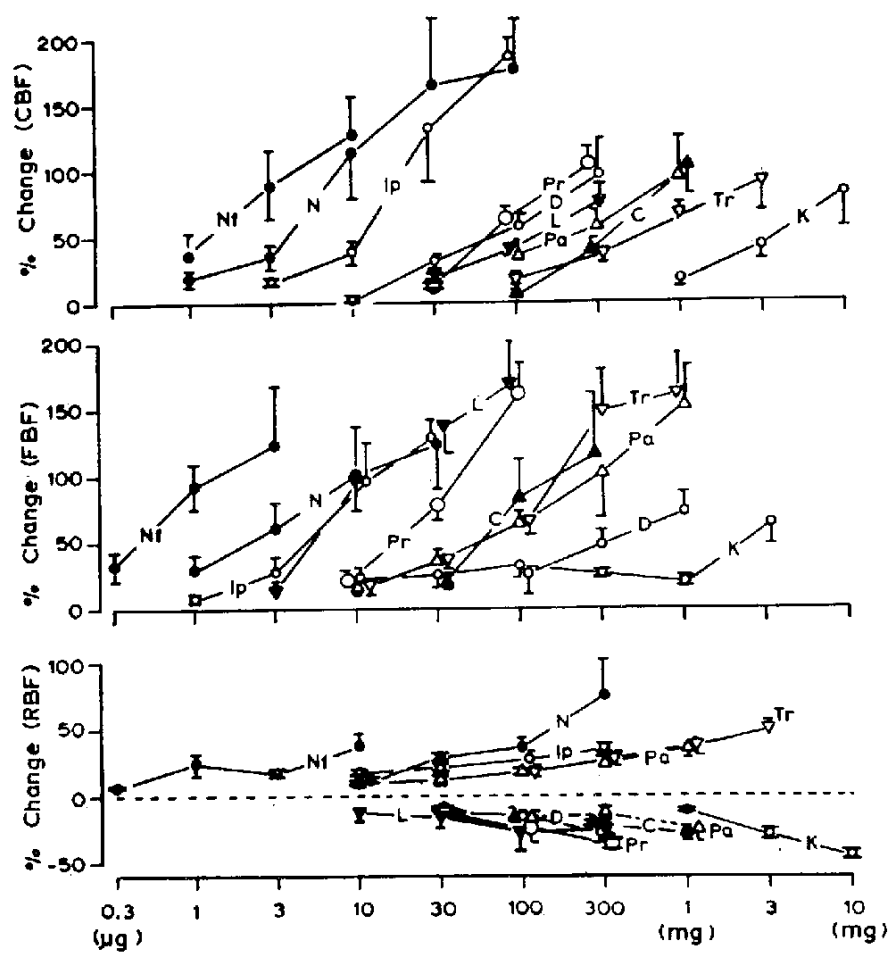

FiG. 2. Dose response curves to the various coronary vasodilators of the coronary (CBF), femoral (FBF) and renal blood flows (RBF). Vertical bars refer to \pm standard errors of the mean ( $n-4$ to 8 ). Ordinates, percent changes in CBF (upper curve), FBF (middle curve), and RBF (lower curve); abscissae, dose in logarithmic scale. Nf ; nifedipine, $\mathrm{N}$; nitroglycerin, Ip ; iproveratril, $\mathrm{Pr}$; prenylaminc, D ; dipyridamole, L; lidofazine, Pa ; papaverine, C ; carbochromene, $\mathrm{Tr}$; trapymin and $\mathrm{K}$; khellin.

The highest dose of nitroglycerin and iproveratril used in this study was $100 \mu \mathrm{g}$. This dose caused approx. a $200 \%$ increase, while the same dose of prenylamine, dipyridamole, lidoflazine, and papaverine showed a $50 \%$ change. Other compounds has no effect. When coronary vasodilating activity of these compounds was evaluated at the dose which caused a $50 \%$ increase in the rate of the coronary blood flow, the following ascending order was obtained: nifedipine >nitroglycerin >iproveratril >dipyridamole, prenylamine, lidoflazine, papaverine, carbochromene, trapymin $>$ khellin, which is approx. equivalent to $1: 1 / 3$ : 1/10:1/100:1/300:1/3000.

Fenoral blood flow (Middle column of Fig. 1 and middle graph of Fig. 2): All of drugs used caused an increase in the rate of femoral blood flow. When the vasodilating activity of these drugs was compared, at the dose which caused a $50 \%$ increase in the rate of the femoral blood flow, the following ascending order was obtained: nifedipine $>$ nitroglycerin >iproveratril, lidoflazine > prenylamine>carbochromene, papaverine, trapymin> dipyridamole $>$ khellin, which was approx. corresponded to $1: 1 / 10: 1 / 30: 1 / 100: 1 / 300$ : 1/1000: $1 / 10000$. Relative potency in the vasodilating activity in the femoral circulation 
followed approx. the same order as seen in the coronary circulation. The pharmacological mechanism may be regarded as similar in both circulations. Lidoflazine caused an increase in the rate of femoral blood flow with one-tenth of the dose used in the coronary circulation. Increasing doses of khellin, however, did not cause a dose-dependent increase in the rate of the femoral blood flow.

Renal blood flow (Right column of Fig. 1 and lower graph of Fig. 2): Nifedipine, nitroglycerine, iproveratril and trapymin caused an increase in the rate of renal blood flow, however, responses to these compounds were weaker than those observed in the coronary and femoral circulations. On the other hand, carbochromene, lidoflazine, dipyridamole, prenylamine and khellin caused a dose-dependent decrease in the rate of renal blood flow. Papaverine in high doses $(100 / \mathrm{g}-1 \mathrm{mg})$ showed a diphasic response in renal circulation.

Comparison of the duration of response in the coronary, femoral and renal circulations to various drugs

Duration of response in the coronary, femoral and renal circulations was compared at the dose which induced the peak response of $50 \%$ above the initial value in the coronary and femoral circulations, but that of $30 \%$ in the renal circulation. The half time as an index of the duration of response was measured according to the elapse of time until the flow rate relurned to the level of $50 \%$ of the peak response. As is summarized in Table 2, rifedipine, dipyridamole, carbochromene and khellin induced long-lasting responses in the coronary circulation, while nitroglycerin, iproveratril and trapymin were shortacting. Duration of responses to papaverine, prenylamine and lidoflazine was between that of the former two groups. Responses in the femoral circulation were generally much shorter. In the renal circulation responses observed were cither vasodilation or vaso-

TARLE, 2. Comparison of the duration of peripheral vascular responses to various vasodilators. Time elapsed to return to a half of the peak response which resulted in a fifty percent increase in the coronary and the femoral blood flows and a thirty percent increase or decrease in the renal blood flow.

\begin{tabular}{|c|c|c|c|c|c|}
\hline \multirow[t]{2}{*}{ Drug } & \multicolumn{2}{|c|}{ Coronary yessel } & \multicolumn{2}{|c|}{ Femoral vessel } & Renal vessel \\
\hline & Dose & sec & Dose & $\mathrm{sec}$ & Dose \\
\hline Nitroglycerin & $10 / \mathrm{g}$ & $43.0 \div 5.6(7)$ & $1 / ! \mathrm{g}$ & $25.5 \div \quad 4.2(4)$ & $15.0 \div 4.2(5)^{\mathrm{a})}$ \\
\hline Nifedipine & $1 / / g$ & $208.0+35.4(5)$ & $0.3 / / \mathrm{g}$ & $50.0 \div 14.0(5)$ & $51.0 \leq 7.5(6)$ \\
\hline Iproveratril & $10 \mu \mathrm{g}$ & $98.0+14.0(6)$ & $1 / 1 \mathrm{~g}$ & $65.0 \pm 12.6(7)$ & $100 \mu \mathrm{g} \quad 156.0 \pm 24.5 \quad(5)$ \\
\hline Papaverine & $300 / \mathrm{g}$ & $133.0 \pm 43.0(6)$ & $30 t / \mathrm{g}$ & $17.0 \perp 2.0(6)$ & $300 \mu \mathrm{g} \quad 64.0+14.0(7)$ \\
\hline Trapymin & $300 \mu \mathrm{g}$ & $43.01-9.0(7)$ & $30 \mu \mathrm{g}$ & $13.0 \mathrm{~L} \quad 1.0(7)$ & $31.0 \pm 4.6(5)$ \\
\hline Lidoflazine* & $100 \mu \mathrm{g}$ & $104.0 \pm 23.0(5)$ & $3 / 2 \mathrm{~g}$ & $26.0 \pm 1.0(5)$ & $100 / \mu \mathrm{g} \quad 514.0 \pm 81.0$ \\
\hline Carbochromene* & $300 \mu g$ & $1260.0 \pm 210.0$ & $30 \mathrm{rg}$ & $17.0 \div 0.7(5)$ & $50.0 \pm 14.0$ \\
\hline Dipyridamole* & $100 \mu \mathrm{g}$ & $1090.0 \pm 320.0$ & $300 ! 9$ & $570.0 \pm 159.0$ & $290.0 \pm 40.0$ \\
\hline Prenylamine* & $100 \mu \mathrm{g}$ & $73.0=15.0(5)$ & $30 \mu g$ & $26.0 \pm 3.0(5)$ & $100 / \mathrm{g}$ more than $30 \min _{(4)}$ \\
\hline Khellin** & $3 \mathrm{mg}$ & $466.0 \therefore 107.0(5)$ & $103 n g$ & $47.0 \div 12.0(4)$ & $1 \mathrm{mg} \quad 64.0 \pm 11.0(5)$ \\
\hline
\end{tabular}

a) Values are expressed as mean $\perp S$.E. Parentheses indicate the number of experiments.

* These drugs caused a vasoconstriction in the renal circulation. 
constriction, and were short except when iproveratril, prenylamine and dipyridamole were employed.

\section{DISCUSSION}

Although it is generally agreed that i.v. administration of various vasodilators causes a marked increase in the rate of the coronary blood flow and a decrease in the systemic blood pressure, there have been few reports regarding effects on the peripheral hemodynamics. Direct action of drugs on different areas of peripheral circulation cannot be accurately measured when the drugs induce significant changes in systemic blood pressure. Previously Hashimoto et al, $(7,8)$ suggested that inducing a decrease in the systemic blood pressure utilizing nitroglycerin, papaverine and theophylline perhaps relates to a nonspecific relaxation of smooth muscles of all peripheral vasculatures.

The modified Langendorff's dog heart preparation and the isolated preparations of different peripheral organs which were cross-circulated with a donor dog under a constant perfusion pressure have definite merits when a simple and quantitative comparison of different drugs in various areas of peripheral circulation are to be cstimated, as all influences of systemic blood pressure or extra-cardial factors can be avoided.

All compounds used in this study caused a significant valsoditation in the coronary and femoral circulations, while that in renal vasodilation was slight. As the basal flow rate of the femoral circulation was lower than that of the coronary, it may be as a matter of course that dose-response curves (Fig. 2) of various vasodilators shift to the left as compared with those in the coronary circulation. Although the degree of vasodilation induced by these drugs in the coronary circulation was similar to that observed in the femoral, responses of the femoral artery were significantly weaker than those of the coronary artery. Therefore it is assumed that the coronary circulation is significantly dilated by these drugs. The dose-response curve produced by dipyridamole in the femoral circulation, however, shifted slightly to the right as compared with that in the coronary. It can be concluded that dipyridamole perhaps cause a greater vasodilation in the coronary circulation.

Furthermore, prenylamine, dipyridamole, lidoflazinc, carbochromene, khellin and a large dose of papaverine caused a renal vasoconstriction as did adenosine (7), while nifedipine, nitroglycerin, iproveratril and trapymin caused a vasodilation not only in the renal but also in femoral circulation (Fig. 1, 2). It was previously demonstrated that the coronary $(11,12)$, femoral $(13)$ and renal $(10,14)$ circulations all possess a metabolic autoregulation mediated by adenosine. Sakai ct al. (10) and Hashimoto and Kokubun (14) observed the adenosine...catccholamine interaction in renal circulation, which suggests a role in the autoregulatory mechanism of peripheral circulation. Conclusively, certain vasodilators may enhance a mechanism in metabolic autoregulation in peripheral circulation.

Carbochromene, lidoflazine, dipyridamole and khellin may be classified as "specific coronary vasodilators", while nifedipine, nitroglycerin, iproveratril and trapymin are "non- 
specific coronary vasodilators". Other compounds such as prenylamine and papaverine appear to belong to another group, as mechanisms of these compounds are assumed to interact with adrencrgic mechanisms $(15,16)$.

Acknowledgements: The authors express their thanks to Prof. Kroneberg for provision of nifedipine. This study was partly supported by grants from Nippon C. H. Boehringer Sohn and Kohjin Co, Laboratories and the Pharmacological Research Foundation Inc. Thanks are also due to Miss R. Horiuchi for preparing the manuscript.

\section{REFERENCES}

1) FAM, W.M. AND MCGrEgor, M.: Circulation Res. 22, 649 (1968).

2) Winbury, M.M.: Circulation Res. 28, I-140-I-147 (197I)

3) Winbury, M.M., Howe, B.B. ANd Hefner, M.A.: J. Pharmacol. exp. Ther. 168, 70 (1969)

4) Wisisury, M.M. and Lloyd, P.G.: Am. J. Physiol. 212, 1062 (1962)

5) Schnaar, R.L. and Harvey, V.S.: Am. J. Physiol, 223, 223 (1972)

6) Frolich, E.D.: Am. J. Physiol. 204, 28 (1963)

7) IJashimoto, K., Kumakura, S. and Tanemura, I.: Arzmeim.-Forsh. 11, 1252 (1964)

8) Hashimoto, K. and Kumakura, S.: Japan. J. Physiol. 15, 540 (1965)

9) Hashmoto, K., Siligli, T., Imal, S., Saito, Y., Yago, N., Uli, I. and Clark, R.E.: Am. J. Physiol. 198, 965 (1960)

10) Sakal, K., Yasuda, K. And Hashimoto, K.: Japan. J. Physiol. 18, 673 (1968)

11) Berne, R.M.: Am. J. Physiol. 204, 317 (1963)

12) Berne, R.M.: Physiol. Rev. 44, 1 (1964)

13) Miura, M., Tominaji, S. and IHashimoto, K.: Arzheim.-Forsch. 17, 976 (1967)

14) Hashimoto, K. and Kokunun, H,: Proc. Soc, exp. Biol. Med, 136, 1125 (1971)

15) Juoro, A.V. ANd VoGT, M.: Br. J. Pharmacol. Chemother. 24, 566 (1965)

16) Goodman, L.S. and Gilmax, A.: The Pharmacological Basis of Therapeutics. cd. 4th, p. 753, Macmillan, New York. 